\title{
APROXIMACIÓN AL VALOR DE LA PREGLUSIÓN EN LA JUSTICIA DE FAMILIA CHILENA. A PROPÓSITO DE UN ESTUDIO APLICADO*
}

\author{
APPROACH TO THE IMPORTANCE OF PRECLUSION \\ IN THE CHILEAN JUSTICE OF FAMILY. A CONTRIBUTION \\ TO AN EMPIRICAL ANALYSIS
}

\section{Francesco CARRETTA MUÑOZ**}

Resumen: La justicia de familia en Chile experimentó un cambio cardinal en 2005, al pasar de un procedimiento escrito a uno oral y desformalizado. Sin embargo, a pesar de que han transcurrido 14 años, dentro de los que se han experimentado constantes modificaciones legales, aún no se tiene un cabal entendimiento de la manera en que operan algunos institutos procesales, como la preclusión: las fronteras de las diversas etapas que suceden en las audiencias son menos visibles y suelen difuminarse a la sazón de la oralidad, lo que de alguna manera diluye su aplicación estricta. Lo anterior se detectó a través de un examen cualitativo efectuado a ciertos jueces de familia de Chile. Los resultados de esa investigación, confrontados a parámetros teóricos del instituto en referencia, son los que se dan a conocer en este estudio.

Palabras clave: reforma a la justicia de familia en Chile, proceso de familia, preclusión, audiencias orales.
ABSTRACT: Family justice in Chile underwent a fundamental change in 2005, moving from a written procedure to an oral and unformalized one. However, even though 14 years have elapsed within, which there have been constant legal changes, there is still no complete understanding of the way some procedural institutes operate, such as preclusion: the borders of the various stages that occur in the hearings are less visible and tend to fade at the time of orality, which in some way dilutes its strict application. The foregoing was detected through a qualitative examination carried out on family judges in Chile. The results of this research, confronted with theoretical parameters, are those disclosed in this study.

Keyzoords: Reform to Family fustice in Chile, Family Process, Preclusion, Oral Hearings.

* Artículo recibido el 30 de enero de 2018 y aceptado para su publicación el 7 de marzo de 2019 .

** ORCID: 0000-0002-2552-8552. Profesor de derecho procesal civil de la Facultad de Derecho de la Pontificia Universidad Católica de Valparaíso, Chile. Correo electrónico: francesco.carretta@pucv.cl.

Boletin Mexicano de Derecho Comparado, nueva serie, año LI, núm. 155, mayo-agosto de 2019, pp. 757-777. 
SUMARIO: I. Introducción. II. Descripción general del instituto. III. La preclusión en correlación con el desarrollo de los imperativos procesales presentes en un procedimiento oral. IV. Etapas y fases del procedimiento oral de familia. V. Posibles usos e interpretaciones de algunos jueces versus los parámetros y contornos del instituto.

VI. Conclusiones. VII. Bibliografia.

\section{INTRODUCGIÓN}

Las audiencias orales en los procedimientos de familia están previstas y delimitadas en la ley. En ellas se aprecia una serie de trámites ordenados de manera armónica. Se comienza con una solicitud de las partes, luego se sigue con la prueba y finaliza con una resolución de término. Es la manifestación del esquema clásico: discusión, prueba y sentencia. Entre esas etapas cuyo orden preestablecido se ha ponderado legalmente, la preclusión juega un papel importante, pero que al parecer la oralidad ha diluido. La falta de un aditamento físico o visible de cierre, como acontece en las certificaciones que constan en fojas de un expediente escrito, induce a pensar que carece de utilidad. Lo anterior choca con su finalidad, que es la clausura de espacios procesales por razones de seguridad jurídica.

La situación antes descrita fue pesquisada en un estudio empírico que contó con la colaboración de 27 jueces de familia sobre otro tema que tangencialmente toca el de esta investigación. En él se les preguntó si permitían que las partes ofrecieran pruebas, hicieran alegaciones o efectuaran trámites luego de que había caducado su oportunidad para hacerlo. Cuestión cuya ocurrencia no es escasa. Un buen porcentaje de jueces señaló que admitía dicha posibilidad derechamente, otro tanto lo dejaba a lo que la parte contraría diga luego de conferir traslado, y unos pocos no lo permiten en ningún evento porque entienden que en ellas ha operado la preclusión.

La falta de uniformidad en las respuestas, ya que las opciones expuestas no son complementarias, denota severas dudas en la aplicación del instituto, lo que, según este estudio, se puede deber a dos circunstancias: i) que no hay un acabado entendimiento de la preclusión, lo que va de la mano con que su vigencia es implícita en la legislación y la escasa doctrina reciente que existe sobre ella, y ii) que, si bien se sabe lo que el instituto significa, la oralidad produce un efecto traslucido sobre los márgenes que delimitan las fases establecidas en un procedimiento oral, que hace que pierda efectividad.

Esta obra está bajo una Licencia Creative Commons

Atribución-NoComercial-SinDerivar 4.0 Internacional, IIJ-UNAM.

Boletín Mexicano de Derecho Comparado, núm. 155, mayo-agosto de 2019, pp. 757-777. 
Cabe aclarar que, lo que se dirá a continuación es sobre la base del procedimiento ordinario para el conocimiento de las materias que caben dentro de la competencia señalada en el artículo 8o. de la ley 19.968. Se exceptúan los procedimientos especiales, sobre todo los referidos a la aplicación de medidas de protección. La razón de la exclusión se vierte en el hecho que, a parte de la diferencia ritual, los parámetros sustantivos y adjetivos por los que transitan aquellos procedimientos son suficientemente disimiles al procedimiento ordinario, como para que lo que se pueda predicar sobre ellos, no quede comprendido en esta pesquisa.

\section{DESGRIPGIÓN GENERAL DEL INSTITUTO}

\section{Objetivos}

Con lo que se describirá en este apartado se pretende evidenciar que la preclusión es un instituto con un ingente desarrollo a lo largo de la historia de la dogmática procesal moderna, con contornos bien definidos y que posee una gran ventaja en todo el orden adjetivo civil, con independencia de la estructura y tipo de proceso del que se trate. Lo anterior servirá para delimitar una base comparativa para el cotejo que se propone en el análisis de campo propuesto en el apartado V.

\section{Origenes y definición}

El estudio y la difusión de la preclusión adjetiva se encuentra en la obra de Chiovenda, aunque su origen es anterior y se ubica en la conocida influencia que el derecho alemán produjo en el jurista italiano, específicamente en los estudios de Von Büllow sobre el particular (De Santis, 2005: 2641-2669; Tesoriere, 1983: 25-51; Couture, 2010: 187). Es propia del derecho continental, pero también se encuentra presente en el common law, de acuerdo a lo que se reseñará más abajo (Bone, 2003: 232-259).

Tradicionalmente no hay discusión en el hecho que la preclusión (Tesoriere, 1983: 25) es la pérdida, extinción o consumación de una facultad procesal, que se produce por el hecho de haberse ejercitado, por no haberse observado el orden asignado por la ley para su ejercicio, o por haberse cumplido junto a una actividad incompatible con su uso. Se estima que, al igual que la tutela cautelar, sirve para mitigar la lentitud de los procesos 
(Pecchi, 1974: 12-18). Claro está que, si no mediara el cierre de espacios procesales, que es uno de sus fines, las partes podrían volver sobre fases fenecidas o aspectos ya tratados y resueltos, lo que puede hacer engorrosa la tramitación de un proceso y demorarlo indefinidamente. ${ }^{1}$

\section{Función}

La división en etapas de un procedimiento es la expresión de su función ordenadora. Ésta se sustenta con base en imperativos, y comienza con la carga de comparecer. Su incumplimiento desencadena todo el sistema de rebeldías (Carratta, 1995; Rispoli, 1911). De esta manera, se desarrolla progresivamente un orden lógico que conlleva la exigencia de realizar determinados actos en una fase ritual específica, en un espacio temporal (Micheli, 1959: 279-280). Es en este carácter mecánico que agrupa tiempo, espacio y límites de inicio y término, donde la preclusión juega un papel esencial. Es precisamente la compuerta que cierra y, a su vez, permite la apertura de esas zonas dentro del proceso, sin las cuales, no llegaría a su conclusión. Dentro de esa idea, Chiovenda (1960: 319-331) señaló que la máxima preclusión y, por ende, el cierre definitivo de todas las fases se produce en la sentencia definitiva, a través de la cosa juzgada material (Tesoriere, 1983: 34; Luiso, 2007: 175; Sassani, 1988: 162).

\section{Finalidades}

A parte de su finalidad natural, que es resguardar la seguridad jurídica, Liebman (1957: 196) expone que la preclusión responde a la necesidad de "asegurar al proceso un desarrollo expedito y libre de contradicciones". La falta de coherencia se encuentra presente en la preclusión en la medida que esta técnica procesal es asumida como un medio para obstar el uso contradictorio de las facultades de las partes en el proceso (De Santis, 2005: 2643). No es esta una idea que haya estado desde el principio dentro de las características de la preclusión, sino que es posterior (Tesoriere, 1983: 4446). Se señala que esta clase de preclusión - por contradicción - es la manifestación menos profundizada del instituto (Gandulfo, 2009: 122-189), se encuentra contenida en aquellas disposiciones legales que extinguen una

1 También el término se utiliza en el derecho sustantivo. Véase Ranieri (1971).

Esta obra está bajo una Licencia Creative Commons

Atribución-NoComercial-SinDerivar 4.0 Internacional, IIJ-UNAM.

Boletín Mexicano de Derecho Comparado, núm. 155, mayo-agosto de 2019, pp. 757-777. 
facultad procesal por la utilización de otra incompatible con aquella. Un ejemplo de esto es el artículo 101 del Código de Procedimiento Civil (en adelante, CPG), que permite el uso del mecanismo de declinatoria o inhibitoria, estableciendo que si se opta por uno, queda vedado el ejercicio del otro.

\section{Transversalidad}

No obstante, las diferencias procedimentales entre las distintas culturas jurídicas (Stürner, 2007: 465-462), quizá por la necesidad preexistente de certeza a la que responde, el instituto es transversal al sistema de justicia. ${ }^{2}$ En el derecho comparado se aprecia en fallos de la Corte Internacional de Justicia (Ovchar, 2009: 1-33). En el ordenamiento norteamericano (Fines, 1995: 607-610) también se aprecia en aquellas situaciones donde la posición contradictoria de una de las partes puede generar un perjuicio en su contendor. Casos acontecidos en aquel ordenamiento han generado un precedente a través de los cuales una persona que efectúa una declaración en la que alguien ha confiado, no podrá más tarde tomar una posición jurídica que contradiga la declaración (Maggs, 2006: 167; Kinsella, 1996: 5354). En el sistema anglosajón, si bien se distingue una subclasificación (Ong, 1999: 136; Kinsella, 1996: 53; Robertson, 2000: 87), sólo el denominado "estoppel per rem judicatam (by record)" se acostumbra a vincular al derecho procesal (Campbell, 1994: 312; Astone, 2006: 106), que es similar a uno de los conocidos efectos de la cosa juzgada, que impide volver sobre lo ya discutido y decidido en un pleito (Taruffo, 1971: 651-687).

\section{Figuras análogas}

Tradicionalmente la preclusión se asocia a otras figuras jurídicas como la renuncia, la caducidad y la prescripción, que al parecer tienden a desplazarla a un área muy restringida de acción. Aquello induce a pensar que se trata de un concepto que, de tan general, resulta innecesario (Balbi, 1983: 23). Estas prevenciones, que provienen de la doctrina italiana, se pueden deber en parte al hecho de que en Italia se identifican además dos figuras

2 Parágrafo 28.3 de los Principles of Transnational Civil Procedure (ALI/UNIDROIT), comentario P-28 C del mismo apartado. 
análogas al concepto en estudio. La decadenza, que puede asimilarse a la caducidad y que consiste en extinción de un derecho o de una facultad por el fallido ejercicio del mismo dentro de un término preestablecido (Mandrioli, 2007: 242-244). También se conoce la acquiescenza expresa o tácita, recogida en el artículo 329 del Codice. La primera es la manifestación de voluntad de una parte, señala expresamente, que no impugnará un acto procesal viciado y perjudicial para ella. La tácita se produce cuando el sujeto, luego de ocurrido el vicio, realiza cualquier acto que no importe su reclamo. La segunda se concreta por un comportamiento absolutamente incompatible con la voluntad del acto procesal, que es por tanto asimilable a la preclusión por contradicción (Scalese, 2000: 104).

\section{Críticas al instituto}

La primera objeción, a la que en parte se aludió en el apartado precedente, señala que sus efectos quedan subsumidos en otras figuras sustantivas como la prescripción, la caducidad y la renuncia. En otras palabras, que la excesiva generalidad del concepto pone en tela de juicio su provecho (Balbi, 1983: 23).

El otro cuestionamiento lo ejercen Satta y Punzi (2000: 238; véase también Scalese, 2000: 101), refiriéndose a la preclusión por contradicción. Exponen que en realidad no se está frente a un instituto propio, sino ante situaciones que la ley regula caso a caso. Una situación jurídica entre las tantas que, coordinada la una con la otra, constituyen el proceso. Incluso, la idea general de la contradicción en este tipo de preclusión hace pensar, sin mucho fundamento, que este mecanismo preclusivo es una expresión del venire contra factum propium en materia procesal. Con lo anterior lleva su observación al complejo campo valorativo del proceso.

$\mathrm{El}$ tercer reproche viene por parte de aquellos que estiman a la figura en referencia como el establecimiento de un inadecuado límite temporal a la actividad defensiva de las partes, producto de la dosis de autoritarismo que Chiovenda imprimió en el CPG italiano de 1942 (Monteleone, 2008: 413-422).

El primer cuestionamiento reseñado al inicio de este párrafo carece de base puesto que no distingue los límites por los que transita el derecho adjetivo y sustantivo. La prescripción y caducidad son propias de la relación civil, y la primera obedece a la sanción por la negligencia del titular de un 
derecho al no haberlo ejercido en el plazo legal. Ninguna de ellas atiende al desenvolvimiento de las relaciones posteriores de los sujetos involucrados en el conflicto. Al contrario, las finiquita por completo. Los fines por ende de todos los institutos son distintos. El área del proceso es mucho más limitada y unidimensional que la propia de una relación sustantiva. Es por lo anterior que la distinción, como señalan algunos autores, ha de notarse en los fundamentos básicos e iniciales de la entidad (Tesoriere, 1983: 72-90).

La segunda objeción expuesta por Satta y Punzi (2000) tampoco encuentra un correlato con la realidad actual del proceso. El posible contenido axiológico de la preclusión por contradicción no supera la línea valorativa imperceptible y supuesta de cualquier norma legal. En especial aquellas que no permite efectuar una conducta desordenada. No se atiende en ellas a la intencionalidad del agente. A su buena o mala fe. La simple constatación del contrasentido hará que se deba cumplir el efecto que impone la norma. La buena fe procesal hoy, no así en los tiempos del jurista italiano, posee un desarrollo que nos permite arribar a tal conclusión; pero no se puede profundizar sobre este aspecto sin que los objetivos propuestos se desvíen a otros cuya extensión no es posible abordar aquí. ${ }^{3}$

El último reclamo, que dice mayor relación con los problemas políticos, que algunos autores notan en el proceso (véase Cipriani, 2007: 45-55; Taruffo, 2006: 95-122), debe descartarse. Primero, porque tal polémica no rinde frutos para lo que se intenta demostrar aquí y porque tales afirmaciones desconocen una constatación histórica. La preclusión es anterior a la presunta influencia autoritaria incoada en el procedimiento civil italiano. En Italia, el mecanismo ya estaba contenido en las leyes que comprendían un proceso de corte privatista y liberal de fines del siglo XIX y principios del siglo XX. Es decir, muchos años antes a la vigencia del cuestionado $\mathrm{Co}^{-}$ dice de 1940 (Rispoli, 1911: 243-244).

\section{LA PREGLUSIÓN EN CORRELACIÓN \\ CON EL DESARROLLO DE LOS IMPERATIVOS PROCESALES PRESENTES EN UN PROCEDIMIENTO ORAL}

Los imperativos procesales son las categorías sobre las que se desenvuelven las conductas que ejercerán los participantes de la contienda y los actos pro-

3 Sobre el particular, véanse Buzzacchi (2002), Cordopatri (2000), De Deus Lima (2005), Picó I Junoy (2003), Romero Seguel (2003) y Taruffo (1999). 
cesales. Lo que puede predicarse sobre ellos no sufre variaciones en un procedimiento escrito u oral. Ello, porque dichos vectores no se refieren a las características intrínsecas (oralidad o escrituración) de las formas procesales que constituyen los escalones por donde transita el procedimiento, si no que a la manera como se ha conformado su matriz temporal a través de la historia de la disciplina (Nieva, 2014: 11-13). Es obvio que éste corre en una secuencia temporal - principio a fin - para llegar a su resultado natural, que es la sentencia o sus equivalentes, por lo que lo referido supone el resultado de la asignación de quienes deben dar fuerza a la secuencia para su avance y el papel que la preclusión juega en tal progresión. Hasta hoy no hay tanta claridad si dicha misión está entregada predominantemente a alguno de los intervinientes, a todos conjuntamente, o sólo a uno de ellos.

Los imperativos procesales (Goldschmidt, 1961: 91; véase también Carnelutti, 1959: 65) interactúan a través de un fenómeno de sinergia, de tal manera que el rumbo que puede tomar una de ellas, determina la suerte de los otros. La carga de la contestación de la demanda determina el deber del juez de llevar a las partes a la faz probatoria, que a su vez sustenta el onus probandi que motiva preponderantemente la carga probatoria de actor. Si se piensa en el contexto descrito sin la preclusión la necesaria armonía que debe existir en la interacción de dichos vectores, para que el proceso se desenvuelva correctamente, se rompe.

Entonces, la preclusión, trátese de un juicio oral o escrito, está dirigida prima facie a motivar la actividad procesal de las partes, toda vez que descansa sobre un mecanismo concebido para que ellas no permanezcan inertes. Este componente se sustenta en la principal consecuencia que asumen los litigantes frente al desembarazamiento de una carga: la pérdida de su derecho (Cappelletti, 2006: 178). Esa secuela se constituye como el impulso necesario para la progresión de los actos del procedimiento. De esta manera, se puede decir que la preclusión es, en buena parte, un dispositivo automático que se erige como una forma de dar respuesta a una necesidad de restringir los plazos de tramitación de un proceso. En otras palabras, es un agente paliativo de la dilación o retardo injustificado. Es por ello que la preclusión puede entenderse dentro de los varios aspectos que (Borges da Silva, 2008: 185-210) sirven al derecho fundamental que tiene todo ser humano a ser juzgado dentro de un plazo razonable (Pedrosa, 2008: 43-62; véase también Marinoni, 2009; Pastor, 2004: 51-76). 
Pero no se detiene en la actividad de las partes, sino que regula también el accionar del juez. Ello es porque, en opinión de Redenti (1977: 70-71), éste se ve afectado por la denominada preclusión pro iudicato. Una cortapisa a las facultades oficiosas del juez, sobre todo en aquellos casos donde le es permitido anular de oficio los actos del procedimiento o cuando puede solicitar prueba no dispuesta por las partes en una fase distinta a la probatoria. ${ }^{4}$ En Chile, esta figura se puede entender comprendida en el desasimiento que está recogido en el artículo 182 del CPC o en aquella figura que impide al juez subsanar las actuaciones viciadas en razón de haberse éstas realizado fuera del plazo fatal indicado por la ley (Ricci, 1998: 258-261). Lo anterior es predicable al procedimiento de familia, como el desordenado e implícito reconocimiento legal de la preclusión en el CPC, por la supletoriedad que dicho cuerpo legal ejerce en la Ley 19.968 (LTF) por el mandato que este último conjunto de normas contiene en su artículo 27.

Se infiere por Tesoriere (1983: 12), tomando en cuenta uno de los cuestionamientos ya vistos (apartado II.7), que la raigambre publicista en el uso del instituto afecta la libertad de las partes dentro del proceso. El argumento es que el uso de una carga impide que ésta se vuelva a ejecutar, lo que de alguna manera constriñe y limita su accionar dentro del proceso. Pero aquella disquisición es solo aparente. No es posible coartar la libertad de las partes en un proceso, como sí ocurre en la esfera de las relaciones humanas, que se desenvuelve fuera de dicho campo. Se cumplen imperativos y formas procesales en aras de la construcción del método que la sociedad ha elegido para solucionar sus conflictos. De alguna manera se asegura su libre desenvolvimiento mediante la fijación de las reglas del juego que, de no existir, sujetaría a los participantes de la contienda a sus propias decisiones y movimientos, lo que naturalmente perjudicaría la libertad del otro (Alvaro de Oliveira, 2007: 340).

Si se atiende a la faz axiológica del proceso, la preclusión no porta un contenido ético. Como se ha tratado de explicar en este apartado, se trata de un aditamento sincrónico en mira a la certeza y rapidez de las etapas del proceso (Rispoli, 1911: 244). Las cargas procesales por sí solas no avanzan

4 Esto, tomando en cuenta las particularidades del proceso civil italiano y en especial lo dispuesto en los artículos 112 y siguientes del Codice. Sobre el particular, véanse Neri (2008: 689-698), Balena (2008: 59-108) y Maccarrone (2008: 669-687). 
escalonadamente sin que preceda a su consumación el instante preclusivo. En otras palabras, el andar mecánico del proceso se detiene sin ella o continúa desordenadamente.

\section{ETAPAS Y FASES DEL PROCEDIMIENTO \\ ORAL DE FAMILIA}

Como se dijo en la introducción, hay que aclarar que dentro del amplio catálogo de materias que actualmente conoce un tribunal de familia, se observan conflictos donde existe un predominio de asuntos que afectan a un niño. Estos problemas dan origen a las causas proteccionales donde se abre un procedimiento especial que posee una estructura simplificada, más oficiosa y donde incluso le es permitido a los intervinientes comparecer sin asistencia letrada. Cuestión similar ocurre en los expedientes por violencia intrafamiliar. Los parámetros en cuanto a la preclusión allí son otros, por lo que no son tratados en este estudio. En todas las demás materias ordinarias contenciosas la LTF dispone de un esquema bipartito para su conocimiento y fallo. Se compone de una audiencia preparatoria y otra de juicio. La primera, como su nombre lo indica, tiene por objeto preparar y filtrar el material que las partes rendirán en la audiencia final. En ambas, como se verá a continuación, hay una serie de trámites que deben ejecutarse ordenadamente.

El artículo 61 enumera varios puntos sobre los cuales se debe desarrollar la audiencia preliminar que culminan, en el parágrafo siguiente, con la resolución que cita a las partes a juicio, donde quedan fijados todos los aspectos tratados con anterioridad. En esta audiencia de preparación existe una sucesión escalonada de actos. No se podría recibir la causa a prueba si el juez no hubiera llamado primeramente a conciliación. Si las partes llegan a acuerdo, todo lo anterior sería inútil. Tampoco es coherente llevar el conflicto a mediación y luego otorgar la oportunidad a una de las partes para que oponga la excepción de incompetencia, y así sucesivamente.

Dentro de todos los puntos tratados específicamente en la norma, se identifican cuatro fases acordes con el siguiente diagrama (artículo 61 de la LTF): 
Fase de discusión

- Exposición de acciones, excepciones y defensas (núms. 1 y 2)

- Posibilidad de decretar cautelares (núm. 3)

Fase de conciliación

- Contiene la posibilidad de derivar el conflicto a mediación o promover una conciliación (núms. 3 y 4)

Fase de prueba

- Determinar el objeto del juicio y los puntos de prueba (núms. 6 y 7)

- Determinar las pruebas presentadas por las partes y/o disponerlas de oficio (núm. 8)

- El prueba anticipada (núm. 9)

Fase de conclusión

- Fijar la fecha de audiencia de juicio (núm. 10)

- Dictar resolución interlocutora que cita a juicio (art. 62)

La audiencia termina con la exposición verbal del juez, que resume lo acontecido y cita a juicio, el cual se debe realizar dentro de los treinta días siguientes o, previo acuerdo de las partes, inmediatamente terminada ésta.

La audiencia de juicio debe realizarse en un solo acto y en su interior se identifican las siguientes etapas:

Inicio (art. 63)

- Verificación de las partes y personas llamadas a declarar

- Manifestación del orden de rendición de pruebas

Prueba (art. 64)

- Rendición de prueba no solicitada oportunamente (art. 63 bis)

- Producción de la prueba

- Opinión del consejero técnico (facultativa)

- Observaciones a la prueba

Sentencia (art. 65)

Esta obra está bajo una Licencia Creative Commons 
Para coordinar el progreso de la etapa probatoria el legislador concede, al inicio, la oportunidad para que sean las partes quienes expresen el orden en que van a rendir sus pruebas, comenzando con la prueba del demandante y finalizando con la del juez. Es interesante destacar que son ellas entonces las que, mediante esta habilitación legal, fijan el instante preclusivo. Este período culminará con las observaciones que demandante y demandado hagan a la prueba rendida y a la opinión del consejero técnico, si ésta fue solicitada por el juez.

Los diagramas no han sido consignados con un afán meramente descriptivo, sino que buscan explicitar y acentuar con mayor rigor el hecho que, no obstante, la oralidad, las fases son definidas y entre ellas hay espacios de apertura y cierre.

\section{Posibles usos E INTERPRetaciones de ALgunos JUEGeS VERSUS LOS PARÁMETROS Y CONTORNOS DEL INSTITUTO}

\section{Análisis de campo}

El epítome de los resultados que se presentan a continuación pertenece a un estudio efectuado a propósito de otro tema de carácter general - la desformalización-, donde se han aprovechado algunos datos arrojados en ella, para la presente pesquisa. ${ }^{5}$ La distinción de campo se nutre de la información recogida en entrevistas personales semiestructuradas, realizadas a 27 jueces de familia de diversas regiones de Chile. ${ }^{6}$ Como se expresó en aquel estudio, el total de magistrados que conforman la muestra, no definen un quantum. No se trató de un estudio estadístico, por lo que no se pretende establecer una cuantificación de la realidad judicial. Se trata de un análisis cualitativo que, conforme a esa característica, hace posible visibilizar un horizonte que engloba una serie de situaciones y discursos que arrojan ciertos

5 La desformalización del procedimiento, sus fundamentos, causas y efectos se encuentran latamente desarrolladas en una investigación cualitativa efectuada entre 2014 y 2016, cuyos resultados fueron exhibidos en las tres publicaciones que se citan a continuación. Una parte del material del trabajo de campo de dicha investigación es usada en este trabajo, véase Carretta Muñoz (2014; 2015; 2017).

6 Los instrumentos de observación y metodología utilizada cuentan con la aprobación y certificación ética para el trabajo con humanos del comité de bioética de la Pontificia Universidad Católica de Valparaíso. 
datos recolectados en entrevistas, por lo que es posible vislumbrar la manera en que piensan en general los jueces, y a su vez, presumir las razones por las cuales toman las decisiones que toman.

Aclarado lo anterior, los patrones detectados en la verificación de campo permiten separar dos grupos: ${ }^{7} i$ la menor parte de los jueces entrevistados, la preclusión sigue operando sin excepciones. Por lo tanto, en los casos planteados en la introducción son de la opinión de anteponerla a cualquier solicitud extemporánea dentro de las mismas audiencias, sin necesidad de plantear un incidente, y ii) la mayoría, cree posible obviarla u omitirla, arguyendo como fundamento la finalidad de hacer menos complejo, más fluido y eficiente el proceso en la medida que se trate de una situación que amerite tal decisión. Las situaciones que justifican ese actuar se trasladan a fundamentos tales como la desigualdad procesal de las partes al notar in situ alguna desventaja en su derecho de defensa. Principalmente, por la falta de asesoría letrada. Esto se refuerza a razón de que cuando la situación cambia, es decir, cuando ambas comparecen con defensa técnica, sí son de la opinión de una aplicación rigurosa del instituto. Salvo, incluso en este último caso, que dicha defensa profesional sea en extremo deficiente.

Otra de las razones que se esgrime con fuerza radica en la idea que ellos tienen de la desformalización. Ésta descansa sobre el tenor literal del artículo 9o. de la LTF que, según sus lecturas, consigna tal directriz como un principio jurídico del procedimiento. Los efectos jurídicos que se le atribuyen, aunque la norma no los define, son que el juez posee facultades

7 Algunas de las opiniones vertidas al estudio que se hace referencia en las notas anteriores, y que fueron consignadas en una de las publicaciones señaladas precedentemente para mayor ilustración, son las siguientes: "Es que creo que la preclusión en un procedimiento oral y desformalizado no es tan estricta, no es absoluta". Juez núm. 15.

"Yo en general trato de marcar los tiempos, pero también debo reconocer que, si llega a suceder una situación como esa en que se le olvidó una prueba, le doy la opción a la contraria, le pregunto «¿Hay algún inconveniente?». Si la contraria no tiene inconveniente la acepto. Si la contraria se opone, entiendo que queda cerrada la posibilidad”. Juez núm. 20.

“Es posible en virtud de la desformalización omitir la preclusión de esas etapas (procesales)? Yo lo he hecho, pero dando traslado. Si la otra parte no tiene ningún inconveniente, que generalmente no lo tienen, sí lo acepto”. Juez núm. 23.

“...a mí me gusta la aplicación de la norma legal... la gente más moderna está más con la teoría de que los principios constituyen derechos, pero como me formé en el criterio de la escrituración, todo el procedimiento (debe ser) escriturado... la gente sabe por qué estoy fallando de esta manera; la publicidad, la transparencia son fundamentales". Juez núm. 24. 
para, en determinadas ocasiones, desatender las formas procesales e incluso restarle valor a la preclusión. En virtud de aquello, puede un demandado ser autorizado para contestar la demanda en la audiencia preparatoria, sin perjuicio de que la ley (sin excepción alguna) prescribe que aquello solo puede ser hecho con anterioridad a los cinco días anteriores a dicha audiencia. En el fondo, pareciera que el alcance que le confiere su impronta de principio jurídico y la función hermenéutica que se les asigna a éstos, facultaría legalmente a los jueces para proceder de esa manera.

\section{Confronte de los posibles usos e interpretaciones del instituto con sus características}

Las conclusiones a las que arriba el examen aplicado permiten visualizar, en general, que algunos jueces no utilizan la preclusión o son indecisos en su aplicación. Luego, la duda es si las razones que tienen en cuenta aquellos magistrados para obrar de esa manera logran desplazar la aplicación estricta del instituto y a su principal fundamento: la seguridad jurídica. En cierto sentido, es confrontar también si dicha actitud está permitida por el derecho vigente. Como se pretende afirmar a continuación, aquello no es posible.

Si a primera vista se puede identificar el valor de la preclusión en una audiencia escrita y en otra oral, cualquier observador dirá que la diferencia está en su base - el procedimiento-, mas no es posible apreciar primariamente, mutatis mutandi, una diferencia en la raíz del instituto. También surge la interrogante de si hay alguna manera trasuntar las características del procedimiento a las características del instituto en el sentido que, per se, la oralidad merma la aplicación del estoppel. No hay razones para ello, pues la estructura del procedimiento sólo cambia el desarrollo de las formas procesales. Una notificación o apercibimiento oral, en audiencia, no varía, salvo en su ejecución, con los fines de dichas actuaciones escritas. En ambos casos se resguarda la bilateralidad de la audiencia y el debido proceso.

Como fue analizado antes (apartado II), la preclusión converge predominantemente en las etapas de los procedimientos y, específicamente, en el momento de cierre y apertura de ellas. Por lo anterior, el acento se debe efectuar en establecer si hay diferencias en los procedimientos orales o escritos en este punto. Entonces, lo primero será dejar en claro que, en un sistema de ley civil, las diversas fases de un procedimiento, sea escrito u oral, 
están delimitados por el legislador, y el valor de la preclusión dependerá de lo que éste manifieste sobre ella. En consecuencia, puede el mismo legislador manifestar excepciones al tránsito riguroso de las etapas de un proceso. Por lo tanto, se debe indagar si en el ordenamiento de que se trate aquella posibilidad está prevista. Por ejemplo, así sucede en España (Garcimartín, 2008: 373-381). El juez en la audiencia de juicio puede, si no se ha ilustrado suficientemente con base en los elementos de convicción incorporados al proceso, "conceder a las partes la palabra cuantas veces estime necesario para que informen sobre las cuestiones que les indique" (artículo 433, núm. 4 LEC 1/2000). Ello implica traspasar autorizadamente la barrera de cierre de la etapa probatoria, tanto para el juez como para las partes.

No hay norma similar en Chile. Si se observan los apartados normativos transcritos líneas arriba, que ordenan la secuencia entre las audiencias que regulan los juicios de familia, y dentro de estas, sus diversas etapas, de acuerdo con lo que se estableció en aquellos diagramas, no se encuentra una ley de similares características. Vale aquí entonces lo que, para el derecho público significa la suma divisio iuris. Es decir, que sólo puede hacerse lo que está expresamente permitido. ${ }^{8}$

Tampoco se observa dentro del elenco de los principios generales establecidos dentro de los artículos de la LTF, alguno que lo permita. Uno de ellos, que podría generar dudas, a saber, la facultad de actuar de oficio establecida en dicha ley no tiene que ver con lo que se predica aquí. Se refiere al poder de dirección que el juez tiene para evitar, por ejemplo, la abundancia innecesaria de pruebas o el poder sobre las alegaciones de las partes en torno a hacerlas menos redundantes. Lo que ha ocasionado algunos reclamos sobre la imparcialidad del juez (Hunter, 2007: 205-229). También, como la misma norma señala, apunta a la expedición de las medidas destinadas a otorgar protección a la infancia o a las víctimas de violencia intrafamiliar.

A su vez, la posibilidad de rendir prueba, fuera del instante establecido por el legislador, establecida en el artículo 61, núm. 9, encuentra justificación en el fundado desconocimiento de la parte de la existencia de ésta al momento de realizarse la audiencia. Similar a aquella situación donde

8 Ténganse en cuenta todas las apreciaciones actuales sobre aquel postulado y la dicotomía público/privado en la que se inserta. Al respecto, véase Vergara Blanco (2010: 115-128). 
se permite a las partes rendir prueba no solicitada oportunamente. ${ }^{9}$ Incluso, atendido que ambas situaciones obedecen a situaciones excepcionales, pueden entenderse como un argumento a favor de comprender que la ley ha sido precisa en establecer un orden de los espacios que las partes tienen para rendirla.

Visto lo anterior, dentro de las razones que repetidamente se esgrimen por algunos jueces, destaca la desformalización. Como ya se expuso antes, aquello fue materia de un extenso análisis que se cruza con éste sólo en este punto, puesto que el primitivo abarca otros ángulos de aquella directriz. Los resultados de dicha investigación, consignados en tres publicaciones, ${ }^{10}$ pueden resumirse en lo siguiente: la desformalización no es un principio jurídico que permite pasar por alto las fases establecidas por la ley. Es una característica inherente a las diversas actuaciones previstas en el entramado normativo establecido para el conocimiento y fallo de los asuntos de familia e infancia, que no tiene una operatividad autónoma. Por ende, no sirve para flexibilizar las formas procesales, ni tampoco para disminuir el valor de la preclusión, que es el objeto de este ensayo.

El otro gran grupo de razones se asilan en una locución que suele aparecer en aquellas sentencias de los tribunales superiores de justicia que aluden a una cuestión más ideológica o política, que jurídica (Ramírez, 2007: 165-185). Es decir, a las razones de justicia material. Al parecer, en la justicia de familia, puede haber un prurito de calificar a priori escenarios donde un sujeto parece desvalido frente a otro. Sin otro antecedente que la mera observación. Aquello, más cercano al prejuzgamiento, no puede ser tomado en cuenta si con ello se puede mermar la seguridad jurídica. ${ }^{11}$ Probablemente, en determinadas ocasiones, se produce el desplazamiento de la barrera que aquel valor implica, en virtud de un razonamiento que toma en cuenta aspectos demasiado concretos, como la vestimenta o apariencia física de un sujeto, y deja de lado cuestiones más abstractas. Puede que la rapidez con que se llevan a cabo los juicios al pulso de la oralidad no permita observar con detención aquellas cuentas que el juez debe sacar cuando debe constituirse en el soporte del sistema de justicia, más allá del caso específico que le corresponde fallar.

9 Artículo 63 bis, LTF.

10 Todas las hipótesis, insumos y fundamentos para llegar a las conclusiones descritas aquí se encuentran en los trabajos citados en el pie de página núm. 44.

11 Con todos los bemoles y amplitud que este concepto posee (Pérez, 1983: 91-93).

Esta obra está bajo una Licencia Creative Commons

Atribución-NoComercial-SinDerivar 4.0 Internacional, IIJ-UNAM.

Boletín Mexicano de Derecho Comparado, núm. 155, mayo-agosto de 2019, pp. 757-777. 
Finalmente, todo lo anterior encuentra una fundada excepción que se puede identificar en una hipótesis, en donde la actividad oficiosa fuera de los límites establecidos en la ley, ${ }^{12}$ o la alegación extemporánea de las partes, puede tener lugar. Es aquella, en el primer caso de oficio y en el segundo a requerimiento, donde el juez puede anular, o las partes pedir la nulidad de los actos o actuaciones que portan un vicio que producen su ineficacia de pleno derecho (Garcimartín, 2008: 377).

\section{Conclusiones}

La preclusión es más patente en un proceso escrito cuyas fases están delimitadas en forma perceptible que en un proceso oral, donde los límites temporales que se encuentran al interior de los hitos que constituyen las distintas etapas del proceso no lo son. Pero el hecho que aquellas fronteras sean más palmarias en un expediente físico que en un juicio oral, no disminuye su principal efecto, que es impedir que los actos se ejecuten inoportuna o inoficiosamente.

Una audiencia, que es un espacio de tiempo delimitado por el transcurso de algunos minutos u horas, debe desarrollarse en un orden sucesivo. Así lo previó el legislador en la LTF al establecer con toda precisión los instantes donde los actos procesales pueden acontecer. Para ello, estableció una fase de discusión, conciliación, oposición de excepciones, análisis probatorio, impugnación de pruebas y conclusión que se gestan minuciosamente dentro de dos audiencias que se desarrollan en una secuencia. Cada periodo se ejecuta teniendo como base el anterior, de manera que el primero debe necesariamente sostener al siguiente y cada uno de ellos está compactado por sus fronteras temporales de inicio y término. Como quedó de manifiesto a lo largo del desarrollo de este trabajo, el mecanismo de apertura y cierre ayuda a la progresión temporal del iter procesal.

Las partes que participan en las audiencias orales del procedimiento de familia saben de antemano las reglas del juego, se forman expectativas en los instantes de clausura de cada periodo, de tal manera que, si a un contendor se le permite abrir una puerta que para ambos había sido cerrada, se produce un desequilibrio injusto. Resulta nítidamente afectada la bila-

12 No se desconoce con esto todo lo expresado a propósito de la preclusión pro iudicato (Redenti, 1977: 70-71). 
teralidad de la audiencia y, en último término, la certeza jurídica. Sucede que, la oralidad parece otorgar un efecto traslucido a aquellos límites, pero esa circunstancia no es fundamento para pasar por alto a la preclusión. Se insiste en el hecho que, si bien las líneas de cierre y apertura de los espacios procesales no son físicamente manifiestos, aquello no inhabilita su vigencia en los procesos de los que se ha hecho referencia.

Algunos jueces chilenos han optado por no aplicar el instituto, pero las razones que esgrimen para ello no han podido traspasar los valores y principios que le sirven de fundamento.

\section{BIBLIOGRAFÍA}

Alvaro de Oliveira, Carlos Alberto, 2007, Del formalismo en el proceso civil, propuesta de un formalismo valorativo, Lima, Palestra.

ASTONE, Francesco, 2006, Venire contra factum proprium, Nápoles, Jovane Editore.

BALBI, Celso, 1983, La decadenza nel processo di cognizione, Milán, Giuffrè.

BALENA, Gianpiero, 2008, "Le preclusioni istruttorie tra concentrazione del processo e ricerca della verità", en BONGIORNO, Girolamo (coord.), Studi in onore di Carmine Punzi, Turín, Giappichelli.

Bone, Robert G., 2003, Givil Procedure. The Economics of Civil Procedure, Nueva York, Foundation Press.

Borges DA Silva Segundo, Edval, 2008, "Preclusão: uma técnica jurídica processual”, Revista do Programa de Pós-Graduação em Direito da Universidade Federal da Bahia, núm. 16.

BuZZACCHI, Chiara, 2002, L'abuso del processo nel diritto romano, Milán, Giuffrè.

Campbelt, Enid, 1994, "Res Fudicata and Decisions of Foreign Tribunals", Sydney Law Review, núm. 16.

CAPPELLETTI, Mauro, 2006, Las sentencias y las normas extranjeras en el proceso civil, Lima, Ara.

Carnelutti, Francesco, 1959, Instituciones del proceso civil, t. I, Buenos Aires, Ejea.

CARRATTA, Antonio, 1995, Il principio della non contestazione nel proceso civile, Milán, Giuffrè.

Carretta Muñoz, Francesco, 2014, "La desformalización del proceso judicial de familia e infancia", Revista de Derecho de la Pontificia Universidad Católica de Valparaíso, Valparaíso, núm. 42.

Esta obra está bajo una Licencia Creative Commons

Atribución-NoComercial-SinDerivar 4.0 Internacional, IIJ-UNAM.

Boletín Mexicano de Derecho Comparado, núm. 155, mayo-agosto de 2019, pp. 757-777. 
CARretTa MuÑoz, Francesco, 2015, "Análisis dogmático sobre la desformalización del proceso judicial de familia chileno. Parte final", Revista de Derecho de la Pontificia Universidad Católica de Valparaíso, Valparaíso, núm. 45.

CARRETTA Muñoz, Francesco, 2017, "Estudio aplicado sobre la desformalización del procedimiento judicial de familia", Revista de Derecho de la Universidad Católica del Norte, Coquimbo, vol. 24, núm. 1.

CIPRIANI, Franco, 2007, "El autoritarismo procesal y las pruebas documentales", Revista Ius et Praxis, vol. 13, núm. 2.

CORdopatri, Francesco, 2000, L'abuso del processo, Milán, CEDAM.

Couture, Eduardo, 2010, Vocabulario jurídico, Santiago de Chile, Editorial Metropolitana.

Chiovenda, Giuseppe, 1960, Instituzioni di diritto processuale civile, t. I, Nápoles, Eugenio Jovene.

De Deus Lima, Patricia Carla, 2005, "O abuso de defesa no processo civil", Revista de Processo, San Pablo, núm. 122.

DE SANTIS, Francesco, 2005, "Riforme processuale e «disponibilità» del regime preclusivo", Studi di diritto processuale civile in onore di Giuseppe Tarzia, Milán, Universitá degli Studi di Milano, Facoltà di Giurisprudenza-Giuffrè.

Fines GLESNER, Barbara, 1995, "The Doctrine of Election of Remedies in Missouri”, UMKC Law Review, vol. 63, núm. 4.

GANDULFO, Eduardo, 2009, "Sobre las preclusiones procesales en el derecho chileno en tiempo de reformas. Ensayo de una teoría general desde un enfoque valorativo jurídico", Revista Ius et Praxis, vol. 15, núm. 1.

GARCIMARTÍN MONTERO, Regina, 2008, "Orden y preclusión en las comparecencias en los procesos civiles", en CAPRI, Federico y ORTELLS RAMos, Manuel (eds.), Oralidad y escritura en un proceso civil eficiente, vol. 2, Valencia, Universidad de Valencia.

GeIGER, Theodor, 1983, Estudios de sociología del derecho, México, Fondo de Cultura Económica.

Goldschmidt, James, 1961, Principios generales del proceso. Teoría general del proceso, t. I, Buenos Aires, Ejea.

Hunter, Iván, 2007, "Poderes del juez civil: algunas consideraciones a propósito del juez de familia", Revista de Derecho de la Universidad Austral de Chile, vol. 20, núm. 1.

KinselLA, Stephan, 1996, "Punishment and Proportionality: The Estoppel Approach", Fournal of Libertarian Studies, vol. 12, núm. 1. 
Liebman, Enrico Tulio, 1957, Manuale di diritto processuale civile, t. I, Milán, Giuffrè.

Luiso, Francesco, 2007, Diritto processuale civile, 4a. ed., Milán, Giuffrè.

MacGarrone, Rosario, 2008, "Contraddittorio e modelli di trattazione fondati sul principio di preclusione", en BONGIORNO, Girolamo (coord.), Studi in onore di Carmine Punzi, Turín, Giappichelli.

MAGgS, Gregory, 2006, "Estoppel and Textualism", American fournal of Comparative Law, núm. 54.

MANDRIOLI, Crisanto, 2007, Corso de diritto processuale civile, t. I, Turín, Giappichelli Editore.

MARINONI, Luiz Guillerme, 2009, "Derecho fundamental a la duración razonable del proceso", Reforma Fudicial. Revista Mexicana de Fusticia, México, núm. 14. Disponible en: https://revistas.juridicas.unam.mx/index.php/ reforma-judicial/article/view/8757/10808.

Micheli, Antonio, 1959, Corso di diritto processuale civile, t. I, Milán, Giuffrè. Monteleone, Girolamo, 2008, "Peclusioni e giusto processo. Due concetti incompatibili", en BongIORNO, Girolamo (coord.), Studi in onore di Carmine Punzi, Turín, Giappichelli.

NERI, Adriana, 2008, "Eccezioni rilevabili dúfficio e preclusión nel proceso ordinario di cognizione", en BongIORnO, Girolamo (coord.), Studi in onore di Carmine Punzi, Turín, Giappichelli.

NIEVA, Jordi, 2014, Derecho procesal I. Introducción, Madrid, Marcial Pons.

Ong, Denise S., 1999, "Equitable Estoppel: Defining the Detriment", Bond Law Review, núm. 11.

OvaHAR, Alexander, 2009, "Estoppel in the Jurisprudence of the ICJ a Principle Promoting Stability Threatens to Undermine It", Bond Law Review, núm. 21.

PASTOR, Carlos Daniel, 2004, "Acerca del derecho fundamental al plazo razonable de duración del proceso penal", Revista de Estudios de la Fusticia de la Facultad de Derecho de la Universidad de Chile, núm. 4.

Peachi Groce, Carlos, 1974, "Algunas consideraciones sobre la preclusión", Revista de Derecho Procesal, núm. 7.

Pedrosa Nogueira, Pedro Henrique, 2008, "Preclusao, venire contra factum propium e duracao razoávelm do proceso", Revista do Programa de PósGraduação em Direito da Universidade Federal da Bahia, núm. 16.

PÉrez LuÑo, Antonio, 1991, La seguridad jurídica, Barcelona, Ariel.

PICÓ I JunOY, Joan, 2003, El principio de la buena fe procesal, Barcelona, Bosch.

Esta obra está bajo una Licencia Creative Commons

Atribución-NoComercial-SinDerivar 4.0 Internacional, IIJ-UNAM.

Boletín Mexicano de Derecho Comparado, núm. 155, mayo-agosto de 2019, pp. 757-777. 
RAMírez CARvajal, Diana María, 2007, "A propósito de la justicia material: reflexiones sobre la justicia en el proceso vs. la justicia material”, Opinión Furídica Universidad de Medellín, vol. 6, núm. 12.

RANIERI, Filippo, 1971, Rinuncia tacita e verwirkung, Pádua, CEDAM.

REDENTI, Enrico, 1957, Diritto proccesuale civile, t. I, Milán, Giuffrè.

RICGI, Gianfranco, 1998, Principi di diritto processuale generale, Turín, Giappicheli.

RisPOLI, Arturo, 1911, Il proceso civile contumaciale, Milán, Editrice Libraria.

Robertson, Andrew, 2000, "Reasonable Reliance in Estoppel by Conduct", University of New South Wales Law Fournal, vol. 87, núm. 2.

Romero Seguel, Alejandro, 2003, "El principio de la buena fe procesal y su desarrollo en la jurisprudencia, a la luz de la doctrina de los actos propios", Revista Chilena de Derecho, núm. 30.

Sassani, Bruno, 1988, Impugnativa dell atto e disciplina del rapporto, Pádua, GEDAM.

SATTA, Salvatore y PunzI, Carmine, 2000, Diritto processuale civile, Pádua, CEDAM.

SCALESE, Giancarlo, 2000, Diritto dei trattati e Dovere di Coerenza nella condotta. Nemo Potest Venire Contra Factum Proprium, Nápoles, Editoriale Scientifica. STÜRNER, Rolf, 2007, "Derecho procesal y culturas jurídicas", Revista Ius et Praxis, vol. 13, núm. 1.

TARUFFO, Michele, 1971, “«Collateral estoppel» e giudicato sulle questioni”, Rivista di Diritto Processuale, vol. 1, núm. 4.

TARUFFO, Michele, 1999, "L'abusso del processo: profili comparatistici", Revista do Proceso, San Pablo, núm. 96.

TARUfFo, Michele, 2006, "Poderes probatorios de las partes y del juez en Europa", Revista Ius et Praxis, vol. 12, núm. 2.

TESORIERE, Giovanni, 1983, Contributo allo studio delle preclusioni nel proceso civile, Pádua, CEDAM.

Vergara Blanco, Alejandro, 2010, "La summa divisio iuris público/privado de las disciplinas jurídicas", Revista de Derecho de la Universidad Católica del Norte, vol. 17, núm. 1. 